\title{
Factors influencing acceptance of optional vaccines in children
}

\author{
Pavan Kumar Jerry. ${ }^{1}$, Manjunatha Babu R. ${ }^{2}$, Susheela C. ${ }^{3}$ \\ ${ }^{1}$ Dr. Pavan Kumar Jerry, Assistant Professor, ${ }^{2}$ Dr. Manjunatha Babu R, Associate Professor, ${ }^{3}$ Dr. Susheela C, Professor \\ \& HOD, all authors are affiliated with Department of Paediatrics, Vydehi Institute Medical Sciences and Research \\ Centre, Bengaluru, Karnataka, India.
}

Corresponding Author: Dr. Manjunatha Babu R, Associate Professor, Department of Paediatrics, Vydehi Institute of Medical Sciences and Research Centre, Whitefield, Bengaluru, Karnataka, India. Email id: manjunath.babu9@gmail.com

\begin{abstract}
Introduction: Immunization has been one of the most significant, cost-effective and stimulatory public health intervention. Vaccines are among the most effective preventive health measures in reducing child mortality, morbidity, and disability. With the rapid growth of big cities, an impending threat of outbreak of vaccine-preventable diseases always exists. It is due to the high population density, continuous influx of a new pool of infective agents with the immigrating population and poor coverage of primary immunization. Vaccinations are best ways to end the serious effects of certain diseases. Methods: A pre-tested structured questionnaire was used to elicit the information like the knowledge of parents on optional vaccines, various socio-demographic factors, about the immunization status and reasons for vaccinating and not vaccinating the child. The method used for the determination of the vaccination status was the vaccination card and the recall method. Results: Of the total 400 children, $3 \%$ are fully immunized and $14 \%$ are unimmunized. Majority of parents has the knowledge about Typhoid vaccine. Over all vaccination rate was decreased with subsequent doses. Common reasons for vaccination are healthy child, prevents disease, disability and increase life expectancy. Most parents say lack of knowledge is the reason for not vaccinating the child. Most unimmunized children belong to families with $\geq 4$ children, rural background, illiterate parents and low socioeconomic status. Conclusions: Study noticed significant association of parental education, socioeconomic status, rural background, number of children in the family and gender discrimination along with unawareness of the parents as main reasons for low immunization coverage.
\end{abstract}

Key words: Children, Immunization, Reasons, Socioeconomic status, Vaccines

\section{Introduction}

Immunization has been one of the most significant, cost-effective and stimulatory public health interventions [1]. Vaccines are among the most effective preventive health measures in reducing child mortality, morbidity, and disability $[2,3]$. About $25 \%$ of under-5 mortality is due to vaccine-preventable diseases. With the rapid growth of big cities, an impending threat of outbreak of vaccine-preventable diseases always exists. It is due to the high population density, continuous influx of a new pool of infective agents with the immigrating population and poor coverage of primary immunization [4,5]. Research conducted in Africa has consistently demonstrated that parental poverty and low educational attainment adversely affect child survival. Research conducted

Manuscript received: $28^{\text {th }}$ December 2017

Reviewed: $9^{\text {th }}$ January 2018

Author Corrected: $17^{\text {th }}$ January 2018

Accepted for Publication: $23^{\text {rd }}$ January 2018 elsewhere has demonstrated that low-cost vaccines against preventable diseases reduce childhood mortality [6]. Vaccine preventable diseases have socio-economic burden on the society. It results in doctor's visits, hospitalizations, poor health and premature deaths. Vaccinations are best ways to end the serious effects of certain diseases. Expenditures for health care contribute to human welfare both directly and indirectly by reducing morbidity and mortality which in turn has a significant contribution to economic growth and political stability.

The National immunization schedule comprises of those vaccines that are given free of cost to all children of the country under Expanded Program of Immunization [7]. It is important to understand the need for optional vaccines along with vaccines in national immunization schedule by health professionals and parents. There is 
need to strengthen health education on vaccination and planning of family budget for vaccination. None of the studies in India have explored the factors influencing acceptance of optional vaccines in children.

\section{Methodology}

This prospective observational study was conducted at a tertiary care medical teaching hospital over a period of one and half years. Children aged 4-6 years were included in the study. A pre-tested structured questionnaire was used to elicit the information from the study participants. Information was collected about the knowledge of parents on optional vaccines, various socio-demographic factors, about the immunization status and reasons for vaccinating and not vaccinating the child. The method used for the determination of the vaccination status was the vaccination card and the recall method. The primary respondent was the mother of the child and in case of her absence, the father was the next respondent. Parents were told to bring vaccination card during each immunization schedule.
Data was collected from parents regarding vaccination of the child with optional vaccines and analysis was done on factors hindering vaccination with optional vaccines. Full immunization was considered if vaccinated against 4 doses of IPV [Injectable polio vaccine], 4 doses of HIB[Hemophilus Influenza B ], 4 doses of pneumococcal, 2 doses of rota virus, 2 doses of hepatitis A, 2 doses of varicella and 2 doses of typhoid in addition to recommendation of UIP [Universal immunization Program]. This is in accordance to Indian academy of paediatrics schedule 2013. Partial immunezation was labelled if he/she had missed any one of the vaccines like IPV, HIB, pneumococcal, rota virus, hepatitis A, varicella and typhoid. Unimmunized if he/she had not taken any of the vaccines like IPV, HIB, pneumococcal, rota virus, hepatitis A, varicella and typhoid. Statistical Methods: Descriptive and inferential statistical analysis has been carried out in the present study. Chi-square/ Fisher Exact test has been used to find the significance of study parameters on categorical scale between two or more groups.

\section{Results}

A total of 400 children were included in the final analysis. The immunization status of the study children was $12(3 \%)$ fully immunized, 332(83\%) partially and 56(14\%) were unimmunized. Majority of parents had the knowledge about Typhoid vaccine followed by HIB and Varicella vaccine [Table.1].

Table-1: Knowledge about various Vaccines.

\begin{tabular}{|c|c|c|}
\hline Vaccine & Frequency & Percent \\
\hline IPV & 288 & 72 \\
\hline HIB & 308 & 37 \\
\hline Pneumococcal vaccine & 148 & 40 \\
\hline Rota virus vaccine & 160 & 59 \\
\hline Hepatitis A vaccine & 236 & 73 \\
\hline Varicella vaccine & 292 & 79 \\
\hline Typhoid vaccine & 316 & \\
\hline
\end{tabular}

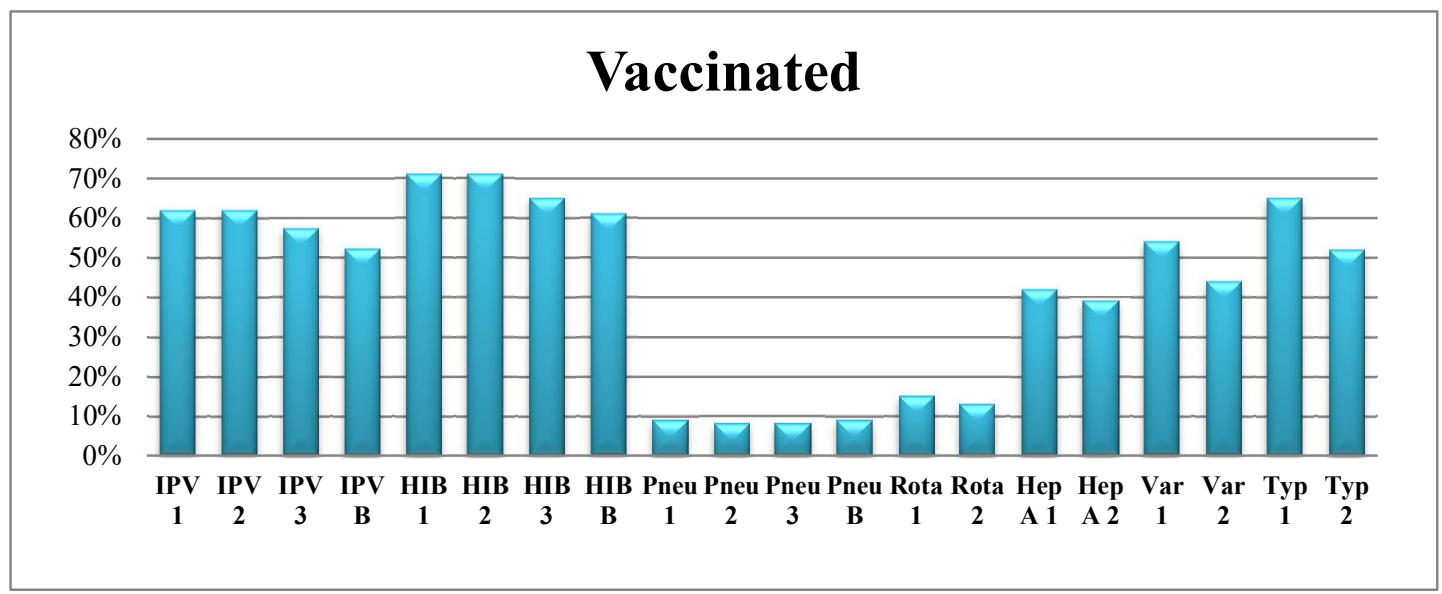

Fig.-1: Vaccination rate of all vaccines 
Maximum vaccination rate was noticed with HIB vaccine followed by IPV and Typhoid. Over all vaccination rate was decreased with subsequent doses [Fig.1].

[IPV 1: Injectable polio vaccine $1^{\text {st }}$ dose, IPV 2: Injectable polio vaccine $2^{\text {nd }}$ dose, IPV 3: Injectable polio vaccine $3^{\text {rd }}$ dose, IPV B: Injectable polio vaccine booster dose, HIB 1: Hemophilus Influenza B $1^{\text {st }}$ dose, HIB 2: Hemophilus Influenza B 2nd dose, HIB 3: Hemophilus Influenza B $3^{\text {rd }}$ dose, HIB B: Hemophilus Influenza B booster dose, Pneu 1: Pneumococcal vaccine $1^{\text {st }}$ dose, Pneu 2: Pneumococcal vaccine $2^{\text {nd }}$ dose, Pneu 3: Pneumococcal vaccine $3 \mathrm{rd}$ dose, Pneu B: Pneumococcal vaccine booster dose, Rota 1: Roatavirus vaccine $1^{\text {st }}$ dose, Rota 2: Roatavirus vaccine 2 nd dose, Hep A1: Hepatitis A vaccine $1^{\text {st }}$ dose, Hep A2: Hepatitis A vaccine $2^{\text {nd }}$ dose, Var 1: Varicella vaccine $1^{\text {st }}$ dose, Var 2: Varicella vaccine $2^{\text {nd }}$ dose, Typ 1:Typhoid vaccine $1^{\text {st }}$ dose, Typ 2:Typhoid vaccine $2^{\text {nd }}$ dose.]

Table-2: Reasons for vaccination.

\begin{tabular}{|c|c|c|}
\hline Reasons Vaccination & Frequency & Percent \\
\hline Child will be healthy & 368 & 76 \\
\hline To prevent disease & 256 & 12 \\
\hline To prevent disability & 48 & 37 \\
\hline To increase life expectancy & 148 & 19 \\
\hline Vaccination benefits society & 76 & 76 \\
\hline
\end{tabular}

Most common reason for vaccination was child will be healthy with vaccination ( $\mathrm{p}-0.843$ ), followed by to prevent disease ( $\mathrm{p}-0.013)$, to prevent disability $(\mathrm{p}-0.000)$, to increase life expectancy $(\mathrm{p}-0.000)$ and vaccination will benefit society [Table.2].

Table-3: Reasons for not vaccination.

\begin{tabular}{|c|c|c|}
\hline Reasons for not vaccination & Frequency & Percent \\
\hline Lack of Knowledge & 220 & 35 \\
\hline To vaccinate during next visit & 132 & 17 \\
\hline Fear of side effects & 68 & 83 \\
\hline Child was ill & 132 & 19 \\
\hline Inconvenient time & 32 & 42 \\
\hline Busy with other works & 76 & 6 \\
\hline Financial constraints & 168 & 27 \\
\hline Far distance & 24 & 32 \\
\hline Multiple pricks & 108 & 5 \\
\hline Ignorance & 128 & 5 \\
\hline Past history of chickenpox & 20 & 32 \\
\hline Wrong advice by someone & 20 & \\
\hline
\end{tabular}

Most parents said lack of knowledge was the reason for not vaccinating child ( $\mathrm{p}-0.000)$ followed by vaccination during next visit (p-0.000), fear of side effects (p-0.023), child was ill (p-0.026), inconvenient time (p-0.843), busy (p-0.000), financial constraints $(\mathrm{p}-0.000)$, too far distance ( $\mathrm{p}-0.000)$, multiple pricks ( $\mathrm{p}-0.000)$, ignorance (p-0.000), past history of chickenpox (p-0.149) and wrong advice by someone is the reason for not vaccinating child (p-0.008)[Table..3].

Majority belongs to Hindu religion followed by Christians and Muslims. Most unimmunized children belong to families with $\geq 4$ children. Families with 4 members have decreased immunization.

Unimmunized children are more common in rural background. Vaccination rate is less if parent's education is low, occupation is semi-skilled, unskilled and unemployed [Table 4]. 
Table-4: Factors affecting Immunization Status.

\begin{tabular}{|c|c|c|c|c|c|}
\hline \multirow[t]{2}{*}{ Factor } & & \multicolumn{3}{|c|}{ Immunization } & \multirow[t]{2}{*}{ Total (\%) } \\
\hline & & Full & Partial & Un & \\
\hline \multirow[t]{2}{*}{ Sex } & Male & 4 & 184 & 24 & $212(53)$ \\
\hline & Female & 8 & 148 & 32 & $188(47)$ \\
\hline \multirow{4}{*}{ Religion } & Hindu & 12 & 228 & 48 & $288(72)$ \\
\hline & Muslim & 0 & 20 & 4 & $24(6)$ \\
\hline & Christian & 0 & 80 & 4 & $84(21)$ \\
\hline & Others & 0 & 4 & 0 & $4(1)$ \\
\hline \multirow{5}{*}{$\begin{array}{l}\text { Number of } \\
\text { Children }\end{array}$} & 1 & 4 & 92 & 12 & $108(27)$ \\
\hline & 2 & 8 & 180 & 20 & $208(52)$ \\
\hline & 3 & 0 & 52 & 12 & $64(16)$ \\
\hline & 4 & 0 & 8 & 8 & $16(4)$ \\
\hline & 5 & 0 & 0 & 4 & $4(1)$ \\
\hline \multirow[t]{2}{*}{ Family members } & $<4$ & 8 & 188 & 16 & $212(53)$ \\
\hline & $\geq 4$ & 4 & 144 & 40 & $188(47)$ \\
\hline \multirow{3}{*}{ Residence } & Urban & 12 & 260 & 20 & $292(73)$ \\
\hline & Semi Urban & 0 & 68 & 8 & $76(19)$ \\
\hline & Rural & 0 & 4 & 28 & $32(8)$ \\
\hline \multirow{3}{*}{$\begin{array}{l}\text { Mother's } \\
\text { Education }\end{array}$} & $>10^{\text {th }}$ Stand & 12 & 204 & 0 & $216(54)$ \\
\hline & $\leq 10^{\text {th }}$ Stand & 0 & 128 & 24 & $152(38)$ \\
\hline & Illiterate & 0 & 0 & 32 & $32(8)$ \\
\hline \multirow{3}{*}{$\begin{array}{l}\text { Mother's } \\
\text { occupation }\end{array}$} & Prof/Semi prof & 12 & 28 & 0 & $40(10)$ \\
\hline & Skill/Semi Skill & 0 & 140 & 44 & $184(46)$ \\
\hline & House Wife & 0 & 12 & 164 & $176(44)$ \\
\hline \multirow{3}{*}{ Family Income } & $>20000$ & 12 & 64 & 0 & $76(19)$ \\
\hline & 10000-19999 & 0 & 220 & 4 & $224(56)$ \\
\hline & $<10000$ & 0 & 48 & 52 & $100(25)$ \\
\hline
\end{tabular}

\section{Discussion}

Immunization is still a major and effective tool in fighting against communicable diseases particularly in preventing childhood diseases which account for high morbidity and mortality in young preschool children. Expanded programme on immunization aims at delivering the primary immunization series to at least $90 \%$ of infants. However, inadequate levels of immunization against childhood diseases remain a significant public health problem in resource poor areas of globe.

Accurate measurement of vaccination coverage is an essential step in determining expected reduction in morbidity and mortality from vaccine preventable diseases. In my study the immunization status is based only on the coverage of optional vaccines while other studies have included only Universal Immunization Program vaccines. Multiple responses were obtained from parents regarding reasons for vaccinating child, Healthy child and prevention from disease were most common reasons for vaccination. In our study the most common reasons for not vaccination were lack of knowledge, financial constraints, ill child and multiple pricks. Nirupam et al., in their study noticed that lack of information and lack of motivation [8] as common reasons for low immunization. In the study conducted by Malinikar et al, the common reasons for not vaccination are unwell child, lack of knowledge of immunization schedule and migration to native village [9].

Reasons detected for low immunization coverage in the study by Bhatia et al., are inadequate monitoring and supervision of routine immunization, migration of people to other areas, poor health infrastructure and lack of planning for slum areas [10]. These variations in reasons for un-immunization in different areas and different studies is probably due to variations in the literacy, unavailability of health facility, reduced awareness, under supervision and health monitoring system across the country. Girl child is one of the most marginalized and deprived groups not only in terms of 
social status and access to education but also nutrition and health, such a sex bias in feeding as well as health care has possibly led to increased female mortality in childhood. In our study, 53\% constituted male and $47 \%$ were female. Among males $1.9 \%$ were fully immunized and $11.3 \%$ were unimmunized. Among females $4.3 \%$ were fully and $17 \%$ were unimmunized. Study by S. Nirupam et al., revealed males (39\%) had better immunization than females $(30 \%)$, which is comparable to study conducted by J. Yadav et al., stated coverage levels of males $(63.7 \%)$ are better than females $(57.1 \%)$ [11], and also study conducted by Malinikar, et al., revealed $70.7 \%$ of males are fully immunized compared to females where $29.3 \%$ were immunized [9].

India is a country of villages, people have differed in rural from urban in various factors like literacy, socioeconomic levels, occupation etc. Our study shows $73 \%$ children from urban area, 19\% from semi urban and $8 \%$ from rural area. In urban area $4.1 \%$ are fully immunized and $6.8 \%$ are unimmunized. In rural area $12.5 \%$ are partially immunized and $87.5 \%$ are unimmunized. Study conducted by Bashir Gaash in Kargil also showed better immunization among children of urban (72\%) than rural (62\%) [12]. Study by Singh et al., revealed urban children out numbered rural children in attaining the higher immunization level [13]. So immunization is better in urban areas than rural probably due to easy accessibility and better health care, better health awareness and higher standard of living. India is a country where there is a unity in diversity, consists of various religions, each religion have their own respectable cultures and traditions. Some of the wrong religious customs blunt the immunization coverage. Our study noticed better immunization with Christians followed by Hindus and Muslims. A study by Yadav et al., showed 100\% Christians, 61.5\% Hindus and 50.5\% Muslims are fully immunized [11], study conducted study by Malinikar et al., showed Hindus $(69.9 \%)$ are better immunized than non-Hindus [9], other study conducted by same authors in BIMARU states showed 48.8\% Hindus, 38.7\% Muslims and $73.7 \%$ of Christians are fully immunized [14].

This was due to better literacy and socioeconomic condition of Christians. Our study showed children belonging to higher socioeconomic status were better vaccinated than children of lower socioeconomic status. Similar observations were made by Dalal et al which revealed better immunization among higher socio economic strata as follows, $100 \%$ of class I, $95.8 \%$ of class II $92.1 \%$ of class III, $81.7 \%$ of class IV and $48.6 \%$ of class V were fully immunized [15]. Per capita income in India is among the lowest in the world. Children in medium and high socioeconomic status areas tend to have $10 \%$ to $15 \%$ higher levels of immunization coverage compared to children of low socioeconomic status [15]. Higher levels of education and literacy lead to greater awareness and also contribute to improvement of economic conditions and are a prerequisite for acquiring various skills and better use of health facilities. Our study shows children of illiterate parents are $100 \%$ unimmunized. Children of parents with professional level of education were fully immunized.

Literate mothers are 1.4 times more likely to get their children fully immunized [16]. Freeman reported that provision of information to mothers regarding when to start the immunization and how often the child should be immunized were key factors determining the immunization status, so mother will understand above facts better when she is literate [17]. Children of unemployed fathers are $100 \%$ unimmunized. About $93.2 \%$ children of unemployed mothers are unimmunized. This shows education of mother has impact on immunization of children. $100 \%$ fully immunized children belong to families with 1 and 2 children. $100 \%$ unimmunized children belong to families with 5 children. $28.6 \%$ of unimmunized children belong to family with less than 4 members. About $71.4 \%$ of unimmunized children belong to family with more than 4 members. Family size is also has an impact on the immunization.

\section{Conclusions}

The study identified significant association of parental education, socioeconomic status, rural background, number of children in the family and gender discrimination along with unawareness of the parents as main reasons for low immunization coverage. Healthy child and disease prevention were the main reasons for vaccinating the child. It can be expected that more stress on identified risk factors in this study may help in improving the immunization coverage. In the last few decades there is an advent of many new vaccines in the Indian market. However, most of these vaccines are at present accessible only to those who can afford to pay for them.

What this study adds? There is a lack of knowledge about optional vaccines, thus there is a need for more awareness and education.

Contribution by different author: Dr. Pavan Kumar Jerry: Sample collection, data entry and References 
Editorial

collection. Dr. Manjunatha Babu R: Study designing, compiling results, Statistical analysis and discussion. Dr. Susheela C: Over all supervision and guidance.

\section{List of abbreviations used}

IPV: Injectable polio vaccine, HIB: Hemophilus Influenza B, Pneu: Pneumococcal conjugate vaccine, Rota: Rota virus vaccine, Var: Varicella vaccine, Typ: Typhoid vaccine, Hep A: Hepatitis A vaccine, UIP: Universal immunization Program.

Funding: Nil, Conflict of interest: None initiated, Perission from IRB: Yes

\section{References}

1.Jørgen Lauridsen, Jalandhar Pradhan. Socio-economic inequality of immunization coverage in India. Health Econ Rev. 2011; 1: 11. doi: 10.1186/2191-1991-1-11.

2. Omer SB, Salmon DA, Orenstein WA, deHart P, Halsey N. Vaccine Refusal, Mandatory Immunization, and the Risks of Vaccine-Preventable Diseases. N Engl J Med 2009; 360:1981-1988.doi: 10.1056/NEJMsa 0806477 .

3. Nyarko P, Pence B, Debpuur C. Immunization status and child survival in rural Ghana. Population Research Division Working Paper No. 147, Population Council, New York 2001:29.

4. Lodha R, Dash NR, Kapil A, Kabra SK. Diphtheria in urban slums in north India. Lancet. 2000 Jan 15;355 (9199):204

5. Loening WE, Coovadia HM. Age specific occurrence rates of measles in urban, peri-urban and rural environment: Implications for time of vaccination. Lancet 1983; 2(8345):324-6.doi: 10.1016/S0140-6736 (83) 90299-4.

6. Bawah AA, Phillips JF, Adjuik M, Vaughan-Smith M, Macleod B, Binka FN. The impact of immunization on the association between poverty and child survival: evidence from Kassena-Nankana District of northern
Ghana. Scand J Public Health. 2010 Feb;38(1):95-103. doi: 10.1177/1403494809352532. Epub 2009 Nov 2.

7. Vijay Yewale, Panna Choudhury, Naveen Thacker. IAP Guidebook on Immunization 2009-2011, 2011;pp 47-113, 162-167.

8. Nirupam S. UIP in Sarojini Nagar block of Lucknow district. Indian J Comm Med 1991:16(2): 82-4.

9. Malinikar. Primary Immunization Status of Children in Slum Areas of South Delhi - The Challenge of Reaching the Urban Poor, Indian J Comm Med.2001;26 (3):151-154

10. Bhatia V, Swami HM, Rai SR, Gulati S, Verma A, Parashar A, Kumari R. Immunization status in children. Indian J Pediatr. 2004 Apr;71(4):313-5.

11. Yadav J, Singh P. Immunization Status of Children and Mothers in the State of Madhya Pradesh. Indian J Comm Med 2004; 29(3):147-148.

12. Bashir Gaash, Rohini Bhan, Shabnam Bashir. Immunization Status of Infants in a Remote District of Kashmir. Ind J Practic Doct 2004; 1(3): 11-12.

13. Singh P, Yadav R.J. Immunization status of children of India. Indian Pediatr 2000; 37: 1194-1199.

14. Singh P, Yadav RJ , Immunization status of children in BIMARU States Indian J Pediatr 2001; 68 (6): 495-499.

15. Dalal A, Silveira MP. Immunization status of children in Goa. Indian Pediatr. 2005 Apr; 42 (4): 401-2.

16. Chhabra P, Nair P, Gupta A, Sandhir M, Kannan AT. Immunization in urbanized villages of Delhi. Indian J Pediatr. 2007 Feb;74(2):131-4.

17. Williams IT, Milton JD, James BF, Neil M.H.G. Interaction of socioeconomic status and provider practices as predictors of immunization coverage in Virginia children. Pediatrics 1995;96:439-446.

\section{How to cite this article?}

Pavan Kumar Jerry, Manjunatha Babu R, Susheela C. Factors influencing acceptance of optional vaccines in children. Int J Pediatr Res. 2018;5(1):13-18.doi:10.17511/ijpr.2018.i01.04. 